Article

\title{
The Influence of Different Metal Ions on the Absorption Properties of Nano-Nickel Zinc Ferrite
}

\author{
Zhijun Ma *, Changye Mang, Xingyuan Weng, Qi Zhang ${ }^{\circledR}$, Liwei Si and Haitao Zhao \\ College of Mining, Liaoning Technical University, Fuxin 123000, China; mcy0515@163.com (C.M.); \\ wengxingyuan2008@163.com (X.W.); zhangqi8891@163.com (Q.Z.); sogoho@126.com (L.S.); \\ haitaozhao0718@126.com (H.Z.) \\ * Correspondence: zhijunma0930@126.com; Tel.: +86-139-4188-1359
}

Received: 2 March 2018; Accepted: 9 April 2018; Published: 11 April 2018

\begin{abstract}
The hydrothermal method was used to dope different amounts of $\mathrm{Co}^{2+}, \mathrm{Mn}^{2+}$, and $\mathrm{Cu}^{2+}$ in nano-nickel zinc ferrite powder. X-ray diffraction (XRD), a scanning electron microscopy (TEM), and a vector network analyzer (VNA) were used to explore the influence of doping on particle size, morphology, and electromagnetic wave absorption performance. Pure nanometer cobalt nickel zinc ferrite phase was prepared using the hydrothermal method with an increasing $\mathrm{Co}^{2+}$ content. Results showed that the grain type structure changed from a spherical structure to an irregular quadrilateral structure with the average particle size increasing from $35 \mathrm{~nm}$ to $60 \mathrm{~nm}$. The lattice constant increased from 0.8352 to $0.8404 \mathrm{~nm}$ with $\mathrm{Co}^{2+}$ doping. The increasing $\mathrm{Co}^{2+}$ can change the position of the absorption peak, increase the bandwidth of the absorber, and improve the performance of the materials in GHz low frequency. The doping ratio of $\mathrm{Mn}^{2+}$ can affect the size of the lattice constant, but nanocrystals are easy to reunite without improving the electromagnetic loss. However, the absorbance performance decreases. For the doping of $\mathrm{Cu}^{2+}$, there is an agglomeration phenomenon. When the doping quantity is 0.15 , the absorbing wave performance becomes better.
\end{abstract}

Keywords: hydrothermal method; ferrite; microwave absorbing properties

\section{Introduction}

Nano nickel zinc ferrite is a kind of ruby structure of soft magnetic materials. It exhibits excellent absorbing performance due to its high resistivity, high permeability, low dielectric loss, and low temperature coefficient [1,2]. It also plays an important role as an electromagnetic material in high frequency inductive magnetic cores, magnetic recording materials, cable or wireless communications, radio, television, radar, and stealth materials. It has an additional benefit of being a low cost material $[3,4]$.

In the unit cell of spinel ferrite, there are many vacancies produced by an ion valence balance between action and the absence of space, which makes it easy to use another metal as a dopant. Ferrite magnetic loss and changes in absorption performance can be realized by doping metal ions with different electromagnetic wave absorption strengths, frequency band widths, and electromagnetic parameters of controlled regulation $[5,6]$. However, introduction of a dopant does not necessarily improve the performance of the material. Therefore, it is important to study the effect of doping different ions and mixtures in ferrite.

Ramesh S. studied ferrite doped with metal nitrate citric acid ester-based matrix prepared by $\mathrm{Ni}-\mathrm{Zn}$ ferrite nano materials with sol gel combustion produced by $\mathrm{Co}^{2+}$ or $\mathrm{Mn}^{2+}$ and found that it exhibited wave-absorbing properties in the low-frequency phase [7]. A study of ferrites doping by Zhao et al. showed that the dry gel formed by metal nitrates and citric acids can be used to synthesize pure phase ferrite with an average particle size of about $60 \mathrm{~mm}$ through a self-burning process [8]. Xiong et al. studied the electromagnetic parameters of six angular ferrites doped with different 
ions [9]. Using different Mn-Zn ferrite volume integral methods, Adriana M. Gama explored the complex permeability of rubber radar absorbing materials and analyzed the dielectric permittivity [10]. T.J. Shinde studied the properties of nickel zinc ferrite including saturation magnetization, magnetic exchange polarization, and cation distribution [11]. In this paper, the crystal shape and microwave absorbing properties of the samples were compared using the hydrothermal method.

It is difficult for single ferrite absorbing materials to meet the requirements for a good wave absorbing material, which include light absorbing, thin, high quality, wide frequency range, and strong absorption. Therefore, it is necessary to mix ferrite with other absorbents to use the synergistic effect of composite materials as well as the different absorption bands and the absorption mechanisms of multivariate composite materials in order to achieve a better absorbing material. In recent years, the development of composite absorbent materials has been the focus of research in the field of absorbing wave materials [12].

\section{Experimental}

\subsection{Experimental Reagent}

All the chemical reagents including $\mathrm{Fe}\left(\mathrm{NO}_{3}\right)_{3} \cdot 9 \mathrm{H}_{2} \mathrm{O} ; \mathrm{Zn}\left(\mathrm{NO}_{3}\right)_{2} \cdot 6 \mathrm{H}_{2} \mathrm{O} ; \mathrm{Ni}\left(\mathrm{NO}_{3}\right)_{2} \cdot 6 \mathrm{H}_{2} \mathrm{O}$; $\mathrm{Co}\left(\mathrm{NO}_{3}\right)_{2} \cdot 6 \mathrm{H}_{2} \mathrm{O}, \mathrm{MnCl}_{2} \cdot 4 \mathrm{H}_{2} \mathrm{O}, \mathrm{CuSO}_{4} \cdot 5 \mathrm{H}_{2} \mathrm{O}, \mathrm{NaOH}$, and $\mathrm{CH}_{3} \mathrm{CH}_{2} \mathrm{OH}$ are analytical pure (AR); PEG $\left(\mathrm{H}\left(\mathrm{OCH}_{2} \mathrm{CH}_{2}\right)_{n} \mathrm{OH}\right), \mathrm{CP}$; distilled water $\left(\mathrm{H}_{2} \mathrm{O}\right)$ was prepared by the Mineral processing engineering laboratory.

\subsection{Experimental Method}

The amounts of ferric/nickel/zinc nitric acid, cobalt/chlorinated manganese/copper sulphate, and polyethylene glycol varied in each experiment.

The above raw materials were dissolved in $150 \mathrm{~mL}$ of distilled water and polyethylene glycol (PEG) was added to the mixture. The mixture underwent $30 \mathrm{~min}$ of ultrasonic processing to obtain an evenly dispersed solution. The solution was transferred to a flask and then into a water bath where the temperature was held at a constant $40{ }^{\circ} \mathrm{C}$. The solution was stirred at a rate of $180 \mathrm{r} / \mathrm{min}$ for $1 \mathrm{~h}$. During stirring, one drop of $2 \mathrm{~mol} / \mathrm{L} \mathrm{NaOH}$ was added to the mixture every two seconds. This allowed the $\mathrm{pH}$ to be adjusted to 10 to generate the reaction precursors.

After $8 \mathrm{~h}$ of aging at a normal temperature, the supernatant was removed. The lower layer contained the reaction precursor. This was shaken in a stainless steel thermal water kettle.

The water thermal response was monitored at $180{ }^{\circ} \mathrm{C}$ for $8 \mathrm{~h}$ in the crystallization reaction kettle. Afterward, a value of $80 \%$ was obtained. After the reaction, the material was successively washed with distilled water, which was followed by four washes with anhydrous ethanol. The material was then vacuum suctioned and filtered at $80^{\circ} \mathrm{C}$ in a thermostatic drum drying oven. The product was then ground into a powder to yield the nanometer ferrite.

\subsection{Test Sample Representation}

A BRUKER D8 ADVANCE X-ray Diffractometer was used to analyze the compositional phases of the samples. The measurement conditions for these experiments include the following: $\mathrm{b} \mathrm{Cu} \mathrm{K}$ alpha wavelength of $1.5406 \AA, 40 \mathrm{kV}$ voltage, tube current of $30 \mathrm{~mA}$, scanning speed of $10^{\circ} / \mathrm{min}$, and scanning range of $25 \sim 65^{\circ}$. With the Scherrer formula [12], it is possible to estimate the grain size of the sample particles $(\mathrm{D}=\mathrm{k} \lambda / \beta \cos \theta, \mathrm{k}=0.89, \lambda=0.154056 \mathrm{~nm}, \beta$ is half high width of peak, and $\theta$ is diffraction angle). Using a JEOL JEM-2010 transmission electron microscope (TEM), the crystal morphology was analyzed using the values in which the microstructure and particle size resolution was $0.1 \sim 0.2 \mathrm{~nm}$ and the accelerating voltage was $200 \mathrm{kV}$. The samples used for electromagnetic measurements were prepared by homogeneously mixing the hybrid materials with wax (the weight ratio of the prepared powder was about $30 \%$ ) and then the mixture was pressed into a toroid with an outer diameter of $7.0 \mathrm{~mm}$, an inner diameter of $3.0 \mathrm{~mm}$, and a thickness of $2.0 \mathrm{~mm}$. Using an AGILENT HP8722ES vector 
network analyzer (VNA), a coaxial-line method was undertaken to examine the samples' dielectric constant and permeability between 1 and $12 \mathrm{GHz}$ frequencies. With the electromagnetic parameters of absorbing materials $\left(\mu_{r}, \varepsilon_{r}\right)$, the instrument parameters and the test results MATLAB were used to calculate the corresponding absorbing reflectivity and the relationship with the frequency curve. On the basis of the measured data of permittivity and permeability, reflection loss $(R L)$ usually can be calculated by using the equation below.

$$
R L(\mathrm{~dB})=20 \log _{10}\left|\frac{Z_{\text {in }}-1}{Z_{\text {in }}+1}\right|
$$

where $Z_{\text {in }}$ is the input characteristic impedance, which can be expressed as the equation below.

$$
Z_{\text {in }}=\sqrt{\frac{\mu_{r}}{\varepsilon_{r}}} \tanh \left[j\left(\frac{2 \pi f d}{c}\right) \sqrt{\varepsilon_{r} \mu_{r}}\right]
$$

where $\varepsilon_{r}$ and $\mu_{r}$ are the complex permittivity and permeability of the absorber, respectively, $f$ is the frequency, $d$ is the thickness of the absorbent, and $c$ is the velocity of light in free space.

The Loss factor can be calculated by using the following equation.

$$
\tan \delta=\tan \delta_{\mathrm{e}}+\tan \delta_{\mathrm{m}}
$$

where $\tan \delta$ is the loss factor, $\tan \delta_{\mathrm{e}}$ is the dielectric loss $\left(\tan \delta_{\mathrm{e}}=\varepsilon^{\prime \prime} / \varepsilon \prime\right)$, and $\tan \delta_{\mathrm{m}}$ is the magnetic loss $\left(\tan \delta_{\mathrm{m}}=\mu^{\prime \prime} / \mu \prime\right)$.

\section{Results and Discussion}

\subsection{The Influence of Doped $\mathrm{Co}^{2+}$ Content on the Absorbing-Wave Performance of Nano-Nickel Zinc Ferrite}

The XRD patterns of nano $\mathrm{Ni}_{0.6} \mathrm{Zn}_{(0.4-x)} \mathrm{Co}_{x} \mathrm{Fe}_{2} \mathrm{O}_{4}$ for several samples with varying $\mathrm{Co}^{2+}$ content are shown in Figure 1. For all the samples' $\mathrm{X}$-ray diffraction patterns, peak positions correspond with the nickel zinc ferrite (111) crystal plane, (220) face, (311), (400), (422), (511), and (440) faces. The cubic crystal system of the pure spinel structure is represented without the presence of any impurity phases such as seen in alpha $\mathrm{Fe}_{2} \mathrm{O}_{3}$. This indicates that an experimental synthesis of the pure cobalt nickel zinc ferrite phase is possible, but it is difficult to achieve for the dry method of doping ions. When the $\mathrm{Co}^{2+}$ content increases, the diffraction peak intensity decreases first. However, when $\mathrm{Co}^{2+}$ doping reaches $x=0.15$, no missing diffraction peaks are seen, which indicates that the crystallization is complete. The intensity of the (311) Bragg reflection is strong, which suggests that the preferred crystal crystallization orientation is (311). Additionally, the peak is particularly wide, which indicates that the polycrystalline material is nano-sized [13,14]. In applying the Scherrer formula, the average grain size in these cobalt-doped nickel zinc ferrites and the average particle size of the crystal grain increases by $35 \sim 60 \mathrm{~nm}$ with doping while the lattice constant increases from $0.8352 \mathrm{~nm}$ to $0.8404 \mathrm{~nm}$ in Table 1 . The hydrothermal method of doping can allow for the introduction of large elements in the $\mathrm{Co}^{2+}$ lattice, which decreases the solution surface tension. This results in a reduction in the formation of the new phase activation energy. It also avoids the defects of the traditional method, which may promote dopant and ferrite mixing, and also controls the specific amount of dopant in the nanomaterials to maintain a certain stoichiometric ratio.

Figure 2 shows nano $\mathrm{Ni}_{0.6} \mathrm{Zn}_{(0.4-x)} \mathrm{Co}_{x} \mathrm{Fe}_{2} \mathrm{O}_{4}$ TEM micrographs. In the figure, it can be observed that after doping with $\mathrm{Co}^{2+}$, the intrinsically spherical nickel zinc ferrite nanoparticles assumed a more irregular quadrilateral structure. With increasing $\mathrm{Co}^{2+}$ content, the grain size increases, the irregular grain arrangement becomes denser, it exhibits poorer dispersion, and the grain becomes more uneven in size. The average particle size reaches $60 \mathrm{~nm}$, which is roughly the same size as the one obtained with the Scherrer formula in the XRD results. Doping with $\mathrm{Co}^{2+}$ nanometer nickel zinc ferrite can visibly change the direction of the crystal growth. This can affect the samples' surface tension and 
surface energy. The radius of doped $\mathrm{Co}^{2+}$ is $453(\mathrm{pm})$, which is smaller than the radius of $\mathrm{Ni}^{2+}$ or $\mathrm{Zn}^{2+}$. It is possible that it occupies the oxygen ions' tetrahedral hole in a very minute amount, if at all. Priority is taken to enter the octahedra (B) in which part of the $\mathrm{Fe}^{3+}$ ions are removed [15]. The lattice distortion causes distortion of the spinel structure and the grain shape becomes irregular. Additionally, as the $\mathrm{Co}^{2+}$ content increases, the $\mathrm{Co}^{2+}$ that does not enter the crystal structure is dispersed to the grain boundary in which the grain grows significantly larger.

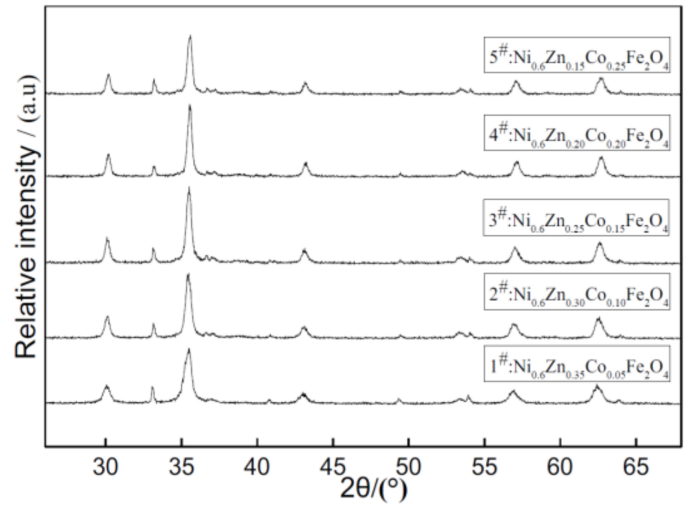

(a)

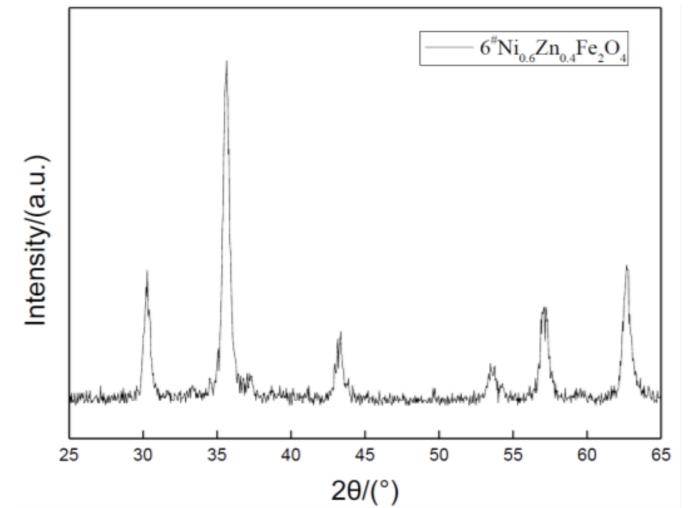

(b)

Figure 1. X-ray diffraction graph patterns of samples prepared with different $\mathrm{Co}^{2+}$ content (a) and without $\mathrm{Co}^{2+}$ content $(\mathbf{b})$.

Table 1. Composition and structure parameters of ferrite.

\begin{tabular}{cccccc}
\hline \multirow{2}{*}{ Structural Formula } & \multirow{2}{*}{$\left.\mathbf{2 \theta} / \mathbf{(}^{\circ}\right)$} & \multirow{2}{*}{$\begin{array}{c}\text { Lattice } \\
\text { Parameter }\end{array}$} & \multicolumn{2}{c}{ (311) Priority Crystallization Diffraction Peak } \\
\cline { 5 - 6 } & & & FWHM/rad & Intensity/a.u. & Size/nm \\
\hline $\mathrm{Ni}_{0.6} \mathrm{Zn}_{0.4} \mathrm{Fe}_{2} \mathrm{O}_{4}$ & 35.62 & 0.8352 & 0.3828 & 468.56 & 20.53 \\
$\mathrm{Ni}_{0.6} \mathrm{Zn}_{0.35} \mathrm{Co}_{0.05} \mathrm{Fe}_{2} \mathrm{O}_{4}$ & 35.53 & 0.8360 & 0.2362 & 411.33 & 34.94 \\
$\mathrm{Ni}_{0.6} \mathrm{Zn}_{0.30} \mathrm{Co}_{0.10} \mathrm{Fe}_{2} \mathrm{O}_{4}$ & 35.49 & 0.8362 & 0.1968 & 460.33 & 41.93 \\
$\mathrm{Ni}_{0.6} \mathrm{Zn}_{0.25} \mathrm{Co}_{0.15} \mathrm{Fe}_{2} \mathrm{O}_{4}$ & 35.44 & 0.8373 & 0.1680 & 555.33 & 49.12 \\
$\mathrm{Ni}_{0.6} \mathrm{Zn}_{0.20} \mathrm{Co}_{0.20} \mathrm{Fe}_{2} \mathrm{O}_{4}$ & 35.58 & 0.8381 & 0.1574 & 499.67 & 52.44 \\
$\mathrm{Ni}_{0.6} \mathrm{Zn}_{0.15} \mathrm{Co}_{0.25} \mathrm{Fe}_{2} \mathrm{O}_{4}$ & 35.34 & 0.8404 & 0.1378 & 487.33 & 59.86 \\
\hline
\end{tabular}

A microwave passing through a medium undergoes three main mechanisms including reflection, absorption, and penetration. As the microwave passes through a glossy dispersive material, its reflection is affected by factors such as complex permittivity, magnetic permeability, sample thickness, and specific surface area. Real permittivity and permeability relate to the amount of polarization in the materials and indicate the ability to store electromagnetic energy. Imaginary permittivity and permeability signify magnetic loss and energy dissipation within a material, which result from conductance, resonance, and relaxation.

Figure 3 exhibits the relationship curve of the tangent delta with frequency variation of the loss factor tangent delta of the nano $\mathrm{Ni}_{0.6} \mathrm{Zn}_{(0.4-\mathrm{x})} \mathrm{Co}_{\mathrm{x}} \mathrm{Fe}_{2} \mathrm{O}_{4}$. As the graph shows, with an increase in frequency, the nano $\mathrm{Ni}_{0.6} \mathrm{Zn}_{(0.4-\mathrm{x})} \mathrm{Co}_{\mathrm{x}} \mathrm{Fe}_{2} \mathrm{O}_{4}$ system of the tan delta value exhibits an overall trend of increasing after first decreasing. However, with an increase in the $\mathrm{Co}^{2+}$ dopant and the change of loss factor, tan delta is nonlinear. When doping $x<0.15$, the tangent of the tangent of the tangent exhibits an increase and, when the quantity is small, the tangent delta is smaller than that of the un-doped parent material. When the dopant amount reaches $x=0.15$, the material loss factor of the strongest peak moves to higher frequency. The peak at 1.25 is significantly more intense than that of other samples. At the same time, to achieve the most effective frequency width, the wave absorption performance is optimal here. When the doping quantity is $x=0.20,0.25$, the effective frequency band widens, but the tangent delta grows smaller and the absorbing effect is not very satisfactory [16]. A comprehensive 
analysis of the electromagnetic loss shows that within the $1 \sim 12 \mathrm{GHz}$ frequencies, when the $\mathrm{Co}^{2+}$ doping amount is 0.15 of the nano $\mathrm{Ni}_{0.6} \mathrm{Zn}_{0.25} \mathrm{Co}_{0.15} \mathrm{Fe}_{2} \mathrm{O}_{4}$, it exhibits an enhanced performance of the electromagnetic wave and electromagnetic loss in which the wave absorption performance is better.

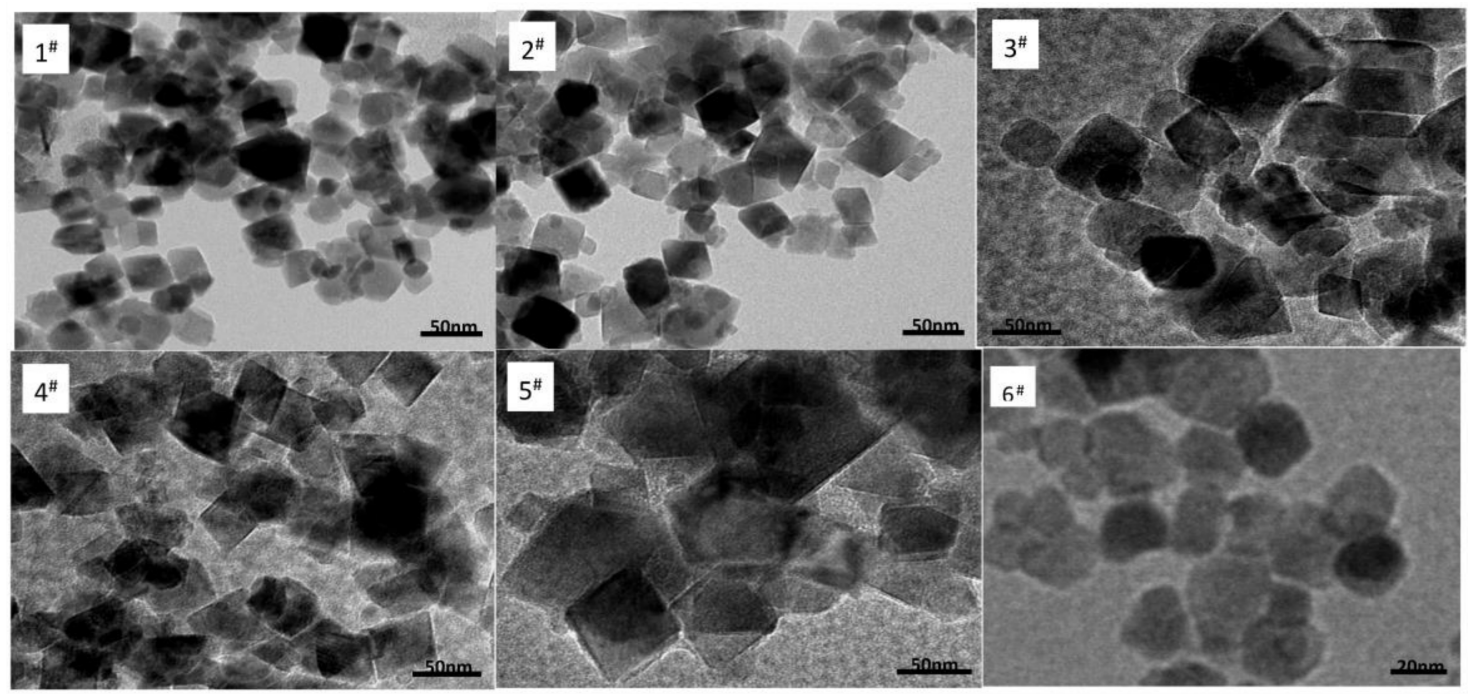

$1^{\sharp} x=0.05 ; 2^{\sharp} x=0.10 ; 3^{\sharp} x=0.15 ; 4^{\sharp} x=0.20 ; 5^{\sharp} x=0.25 ; 6^{\sharp} x=0$

Figure 2. Transmission electron micrograph of samples prepared with different $\mathrm{Co}^{2+}$ content.

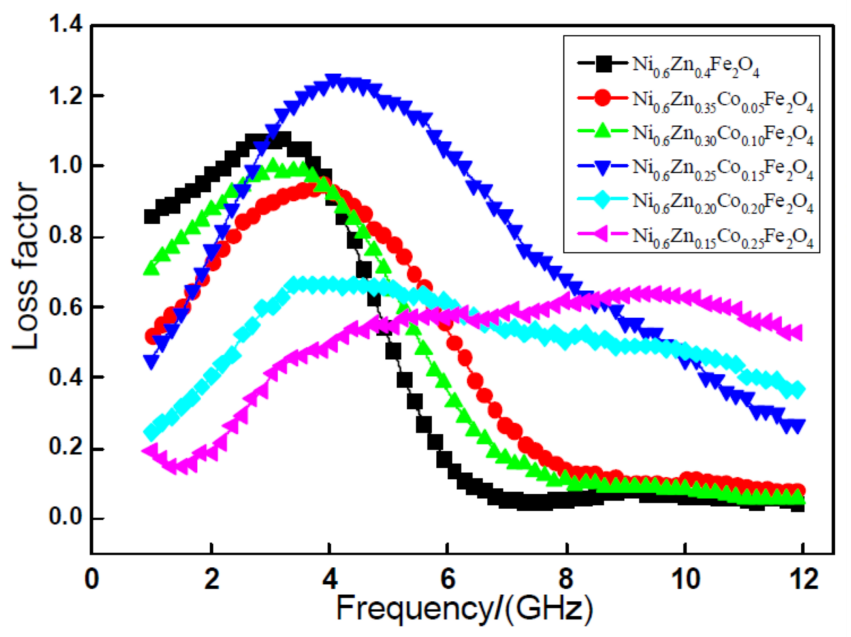

Figure 3. Curves of $\tan \delta$ and frequency for the $\mathrm{Ni}_{0.6} \mathrm{Zn}_{(0.4-x)} \mathrm{Co}_{x} \mathrm{Fe}_{2} \mathrm{O}_{4}$ sample.

This is because the nanometer $\mathrm{Ni}_{0.6} \mathrm{Zn}_{(0.4-\mathrm{x})} \mathrm{Co}_{\mathrm{x}} \mathrm{Fe}_{2} \mathrm{O}_{4}, \mathrm{Ni}^{2+}$, and $\mathrm{Co}^{2+}$ prefer to occupy the octahedra (B). With an increase in the $\mathrm{Co}^{2+}$ content, the grain boundary phase reduces. Demagnetization can decrease this grain boundary growth and increase the strength of $\mathrm{Ni}_{0.6} \mathrm{Zn}_{(0.4-x)} \mathrm{Co}_{x} \mathrm{Fe}_{2} \mathrm{O}_{4}$, which improves the magnetic hysteresis loss of the material. At the same time, with the octahedral crystal lattice distortion (B), the internal stress increases. With less material containing $\mathrm{Fe}^{2+}$, the $\mathrm{Fe}^{2+}-\mathrm{Fe}^{3+}$ electron mobility is reduced. This makes the hole type more conductive and the dielectric loss increase. With an increase in $\mathrm{Co}^{2+}$ content, the octahedral $\mathrm{Co}^{3+}(\mathrm{B}), \mathrm{the}^{\mathrm{C}} \mathrm{Co}^{3+}$ undergoing electron exchange with $\mathrm{Co}^{2+}$, and the octahedron (B) $\mathrm{Fe}^{2+}$ and $\mathrm{Fe}^{3+}$ electronic exchange disappear. As a result, the equivalent electronic exchange decreases and the electrical conductivity is abated. The dielectric constant and loss are also reduced. In this manner, in the nano nickel zinc ferrite, the $\mathrm{Co}^{2+}$ dopant can improve the electromagnetic loss properties of the nickel zinc ferrite 
nanoparticles and can effectively broaden the spectrum. When the doping amount reaches $\mathrm{x}=0.15$, the electromagnetic loss characteristics of the sample are the most positive in which the absorbing effect is the greatest.

Figure 4 shows the relationship curve of the absorbency reflectivity of 2-mm nanometer $\mathrm{Ni}_{0.6} \mathrm{Zn}_{(0.4-x)} \mathrm{Co}_{x} \mathrm{Fe}_{2} \mathrm{O}_{4}$. The figure reveals that, within the $1 \sim 12 \mathrm{GHz}$ band, the nano nickel zinc ferrite absorbing reflectivity is $12.02 \mathrm{~dB}$, which is valid for the $1 \sim 6 \mathrm{GHz}$ frequency band. After doping $\mathrm{Co}^{2+}$, along with an increase in the dopant $\mathrm{x}$, when $\mathrm{x}=0.05,0.10$, the absorbing peak reflectivity is $9.21 \mathrm{~dB}$ and $9.64 \mathrm{~dB}$. When the $\mathrm{Co}^{2+}$ doping quantity is low, the material's absorbing effect is not clear. When the doping quantity $\mathrm{x}=0.15$, the absorbing wave reflectivity is reduced from $-12.01 \mathrm{~dB}$ to $-15.05 \mathrm{~dB}$. The effective band width nearly doubles, but the absorbing wave performance is the highest value. Although an excessive amount of $\mathrm{Co}^{2+}$ doping increased the reflectivity, there was no clear peak value. Even though peaks tend to move to higher frequency, within the test frequency band, the overall wave absorption bands improved significantly. At the same time, by doping $\mathrm{Co}^{2+}$, the absorption peak position can change [17]. The peak value of the curve in the diagram and the corresponding frequency are shown in Figure 3. In this regard, the appropriate amount of $\mathrm{Co}^{2+} \mathrm{can}^{2}$ effectively be used to increase the absorbance frequency and improve the absorbing performance of the material. Doping $\mathrm{Co}^{2+}$ ions in the ferrite use the compensation of negative anisotropy to achieve a stable domain wall and increase the electromagnetic loss. These factors meet the requirements of electromagnetic wave ferrite devices.

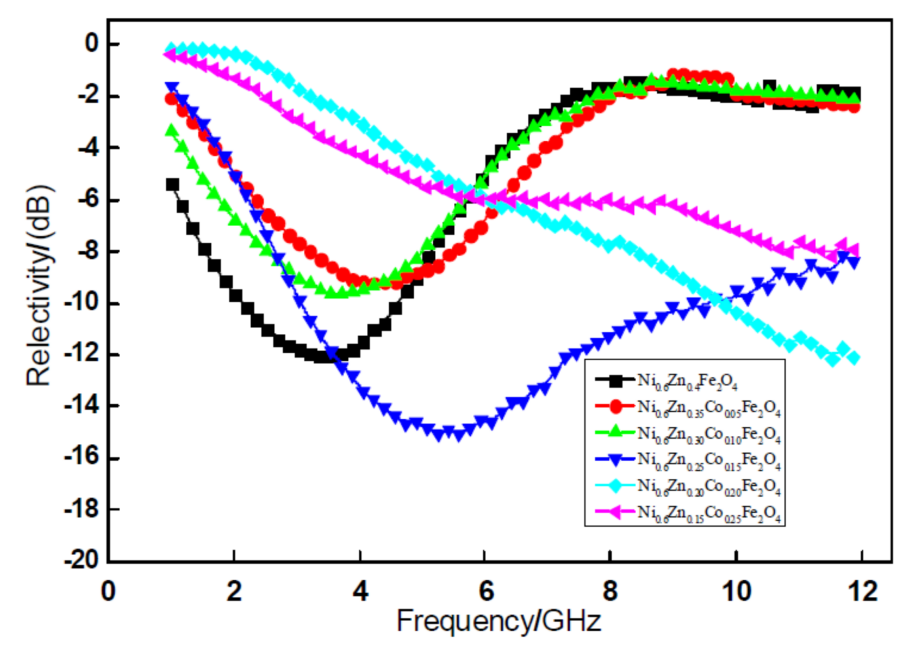

Figure 4. Curves of reflectivity and frequency for the $\mathrm{Ni}_{0.6} \mathrm{Zn}_{(0.4-\mathrm{x})} \mathrm{Co}_{x} \mathrm{Fe}_{2} \mathrm{O}_{4}$ sample.

\subsection{The Influence of $\mathrm{Mn}^{2+}$ Content on the Absorption Properties of Nano-Nickel Zinc Ferrite}

Figure 5 shows the XRD pattern of nano $\mathrm{Ni}_{0.6} \mathrm{Zn}_{(0.4-\mathrm{x})} \mathrm{Mn}_{\mathrm{x}} \mathrm{Fe}_{2} \mathrm{O}_{4}$ mixing different levels of $\mathrm{Mn}^{2+}$. Table 2 exhibits the ferrite component and structure parameters with various $\mathrm{Mn}^{2+}$ content. As can be seen from Figure 5 and Table 2, all the samples, in compliance with the standard atlas JCPDS reference, exist in the single phase spinel structure. No other impurities can be detected and the five main diffraction peaks appear in the sample at $35^{\circ}$. The diffraction peak intensity increases as the amount of $\mathrm{Mn}^{2+}$ doped increases from 346.33 to 574.67 . The peak intensity significantly sharpens with the dopant, which indicates that doping $\mathrm{Mn}^{2+}$ into the crystal lattice does not change the crystal structure. However, it increases its crystallinity and promotes the crystallization of pure phase nanometer nickel manganese zinc ferrite. With an increase in $x$, the (311) crystal plane diffraction Lord peak moves to smaller angles. This is associated with an increase in the lattice constant of the product [18]. The grain size at the same time also experiences a slight increase, but this increase is less than that of the cobalt nickel zinc ferrite nanoparticles. This is because the $\mathrm{Ni}_{0.6} \mathrm{Zn}_{(0.4-x)} \mathrm{Co}_{\mathrm{x}} \mathrm{Fe}_{2} \mathrm{O}_{4}$ ionic radius is larger than that of $\mathrm{Mn}^{2+}$. The dopant may enter the tetrahedron to replace the original small $\mathrm{Zn}^{2+}$ ion radius 
and $\mathrm{Fe}^{3+}$. Due to the volume of $\mathrm{A}$, the crystal structure effect makes the lattice constant change by increasing it from $0.8352 \mathrm{~nm}$ to $0.8440 \mathrm{~nm}$. But the lattice constant decreases when the doping quantity $\mathrm{x}=0.15$, so the doping ratio of $\mathrm{Mn}^{2+}$ affects the size of the lattice constant.

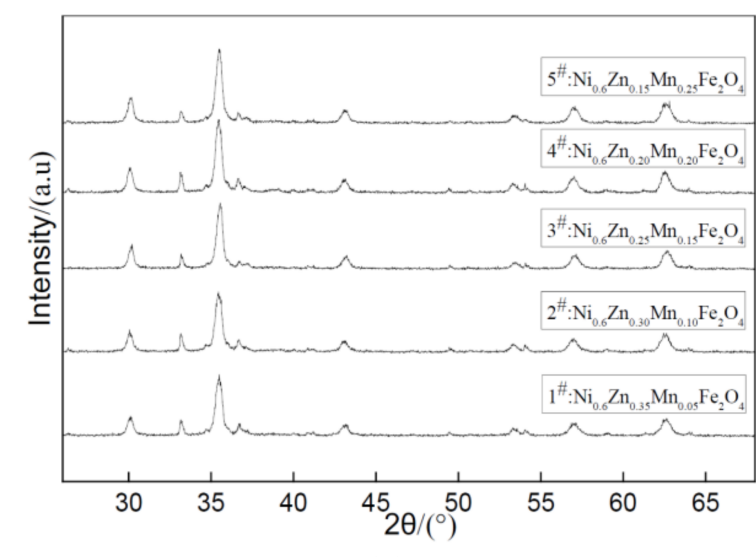

(a)

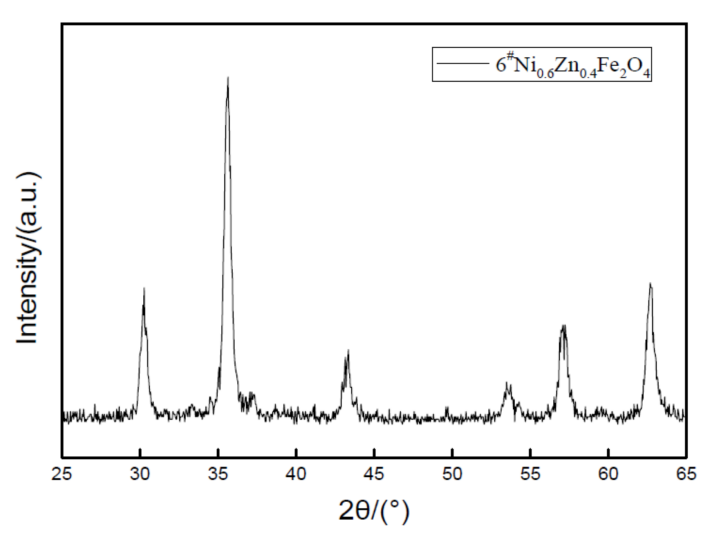

(b)

Figure 5. X-ray diffraction graph patterns of samples prepared with different $\mathrm{Mn}^{2+}$ content (a) and without $\mathrm{Mn}^{2+}$ content (b).

Table 2. Composition and structure parameters of ferrite.

\begin{tabular}{cccccc}
\hline \multirow{2}{*}{ Structural Formula } & \multirow{2}{*}{$\mathbf{2 \theta} /\left(^{\circ}\right)$} & \multirow{2}{*}{$\begin{array}{c}\text { Lattice } \\
\text { Parameter }\end{array}$} & \multicolumn{2}{c}{ (311) Priority Crystallization Diffraction Peak } \\
\cline { 5 - 6 } & & & FWHM/rad & Intensity/a.u. & Size/nm \\
\hline $\mathrm{Ni}_{0.6} \mathrm{Zn}_{0.4} \mathrm{Fe}_{2} \mathrm{O}_{4}$ & 35.62 & 0.8352 & 0.3828 & 468.56 & 20.53 \\
$\mathrm{Ni}_{0.6} \mathrm{Zn}_{0.35} \mathrm{Mn}_{0.05} \mathrm{Fe}_{2} \mathrm{O}_{4}$ & 35.61 & 0.8354 & 0.3023 & 346.33 & 27.31 \\
$\mathrm{Ni}_{0.6} \mathrm{Zn}_{0.30} \mathrm{Mn}_{0.10} \mathrm{Fe}_{2} \mathrm{O}_{4}$ & 35.58 & 0.8362 & 0.2833 & 360.33 & 29.14 \\
$\mathrm{Ni}_{0.6} \mathrm{Zn}_{0.25} \mathrm{Mn}_{0.15} \mathrm{Fe}_{2} \mathrm{O}_{4}$ & 35.24 & 0.8382 & 0.2520 & 488.00 & 32.72 \\
$\mathrm{Ni}_{0.6} \mathrm{Zn}_{0.20} \mathrm{Mn}_{0.20} \mathrm{Fe}_{2} \mathrm{O}_{4}$ & 35.49 & 0.8440 & 0.2475 & 571.67 & 33.34 \\
$\mathrm{Ni}_{0.6} \mathrm{Zn}_{0.15} \mathrm{Mn}_{0.25} \mathrm{Fe}_{2} \mathrm{O}_{4}$ & 35.44 & 0.8395 & 0.2046 & 574.67 & 40.34 \\
\hline
\end{tabular}

Figure 6 reveals a nano $\mathrm{Ni}_{0.6} \mathrm{Zn}_{(0.4-x)} \mathrm{Mn}_{x} \mathrm{Fe}_{2} \mathrm{O}_{4}$ TEM image. The image at the nanometer scale shows that the nickel and manganese zinc ferrite grain size is spherical in nature. There are fewer quadrilateral, loose aggregate surfactant, and large translucent, irregular particle shapes that may form in the reaction process. The fewer $\mathrm{Mn}^{2+}$ content, the smaller the ferrite particles are with most being roughly $30 \mathrm{~nm}$ in size, which is consistent with the XRD results. The grain growth is good and evenly dispersed. However, with an increase in $\mathrm{Mn}^{2+}$ content, the grain grows. With this growth, the particles assume looser, aggregate quadrilateral structures and are relatively dense, uneven in size, and have a mean grain size of $40 \mathrm{~nm}$. They also exhibit poor dispersion and agglomeration. Because of the hydrothermal preparation of nickel and manganese zinc ferrite nano powder, the nanometer grain specific surface area is larger [19]. Due to the influence of the surface effect and the magnetic attraction between the particles and the molecular inter-atomic forces, the particles reunite easily into large aggregates at the interface. This works to reduce the surface and static magnetic energy. At the same time, the grain growth speed is not easy to control and the sizes will differ. The second is capillary contraction in the drying process, which causes the agglomeration.

Figure 7 shows the loss factor tan delta of nano $\mathrm{Ni}_{0.6} \mathrm{Zn}_{(0.4-x)} \mathrm{Mn}_{x} \mathrm{Fe}_{2} \mathrm{O}_{4}$. It does not improve after doping with $\mathrm{Mn}^{2+}$. The nano nickel zinc manganese ferrite magnetic loss, loss factor, tan delta value in the $1 \sim 12 \mathrm{GHz}$ frequency, and the increase of frequency first increased after decreasing. With the increase of $\mathrm{Mn}^{2+}$ dopant, the loss factor, $\tan \delta$ value, does not exhibit a linear change, but is reduced after increasing and then decreases once again. When the doping quantity is $x=0.05,0.10$, the $\tan \delta$ value does not change significantly. When the doping amount is $\mathrm{x}=0.15$, in the $1 \sim 6 \mathrm{GHz}$ frequency, 
it is bigger than the loss factor in the other doped samples. The effective frequency band widens slightly, but is still below the doping tan and the size of the $\tan \delta$ value. When the doping quantity $\mathrm{x}=0.20,0.25$, the $\tan \delta$ value decreases with an increase in doped $\mathrm{Mn}^{2+}$. The excess $\mathrm{Mn}^{2+}$ dopant minimizes the dissipation factor. Doping of $\mathrm{Mn}^{2+}$ in the nano nickel zinc manganese ferrite shows a loss in magnetic performance and does not reach the effect of the wave absorption performance of the reinforced material. This is because the $\mathrm{Mn}^{2+}$ effective magnetic moment is less than that of $\mathrm{Fe}^{3+}$. With the increase in $\mathrm{Mn}^{2+}$ dopant, the $\mathrm{Fe}^{3+}$ concentration is reduced, which results in a decrease in the effective magnetic moment of the nanometer nickel manganese zinc ferrite and the saturation magnetization. This leads to loss in the overall electromagnetic intensity [20].

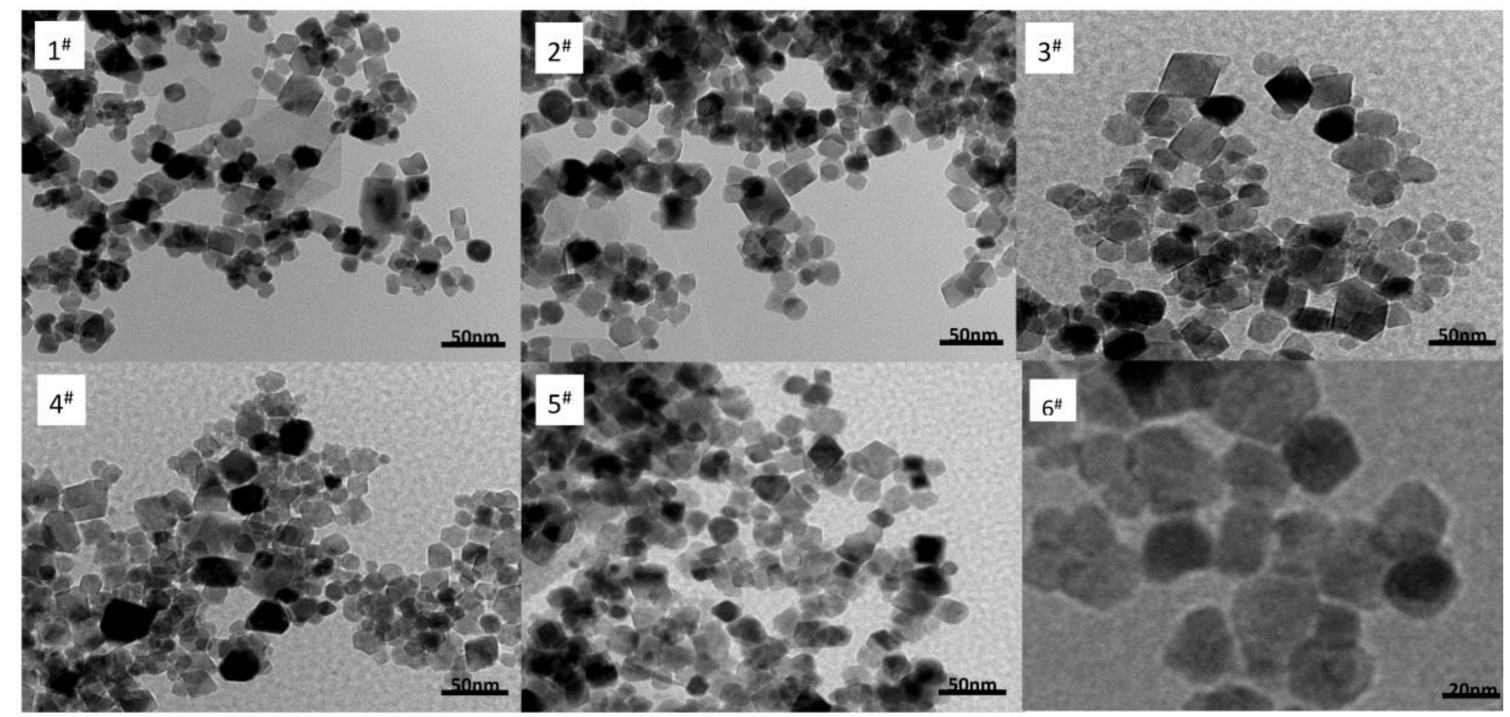

$1^{\sharp} x=0.05 ; 2^{\sharp} x=0.10 ; 3^{\sharp} x=0.15 ; 4^{\sharp} x=0.20 ; 5^{\sharp} x=0.25 ; 6^{\sharp} x=0$

Figure 6. Transmission electron micrograph of samples prepared with different $\mathrm{Mn}^{2+}$ content.

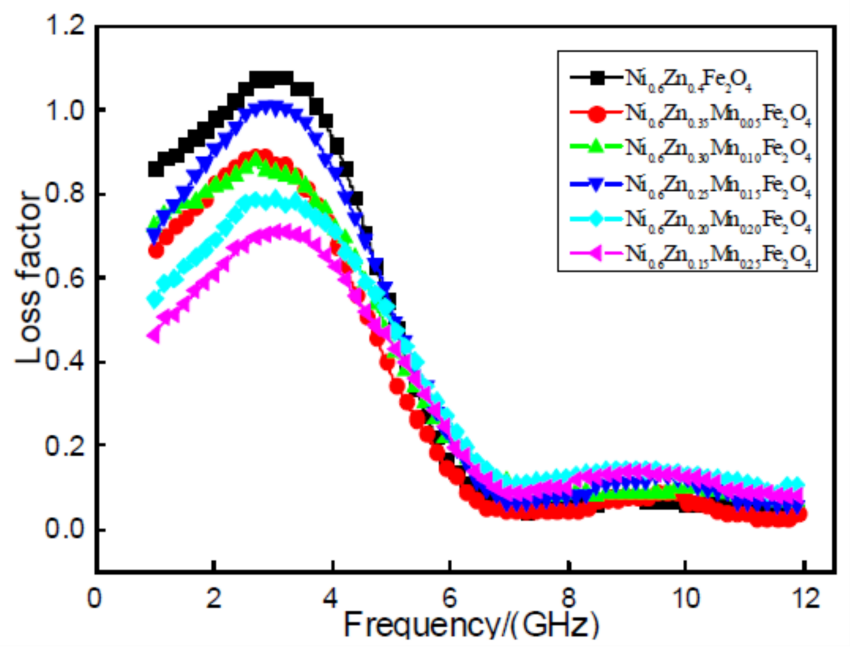

Figure 7. Curves of $\tan \delta$ and frequency for the $\mathrm{Ni}_{0.6} \mathrm{Zn}_{(0.4-\mathrm{x})} \mathrm{Mn}_{\mathrm{x}} \mathrm{Fe}_{2} \mathrm{O}_{4}$ sample.

Figure 8 shows $2 \mathrm{~mm}$ nanoscale $\mathrm{Ni}_{0.6} \mathrm{Zn}_{(0.4-\mathrm{x})} \mathrm{Mn}_{\mathrm{x}} \mathrm{Fe}_{2} \mathrm{O}_{4}$. In the diagram, between the $1 \sim 7 \mathrm{GHz}$ band, the nano nickel zinc manganese ferrite absorbing peak reflectivity is relative to the electromagnetic wave absorbing effect at low frequency. With the increase of $\mathrm{Mn}^{2+}$ doping amount, the absorbing peak reflectivity of the sample is: $9.65 \mathrm{~dB}, 9.31 \mathrm{~dB}, 11.65 \mathrm{~dB}, 8.64 \mathrm{~dB}$, and $7.63 \mathrm{~dB}$. The absorbing reflectivity increased by $12.01 \mathrm{~dB}$ at the doping amount of $\mathrm{x}=0.25-7.63 \mathrm{~dB}$, which is shown 
by the curve in Figure 8 . As a result, the $\mathrm{Mn}^{2+}$ impurity in the nano-nickel-zinc ferrite decreases the absorbing-wave performance of the material. With this decrease in the absorbing effect, the effective band width will not change significantly. This is because when doping with $\mathrm{Mn}^{2+}$, the octahedral $\mathrm{Fe}^{3+}(\mathrm{B})$, the concentration of $\mathrm{Fe}^{2+}$, and the octahedron (B) $\mathrm{Fe}^{2+}$ with its positive magnetocrystalline anisotropy constant are replaced. The $\mathrm{Mn}^{2+}$ negative magnetocrystalline anisotropy constant makes it smaller and, therefore, reduces the electromagnetic loss of the material. This weakens the wave absorption performance.

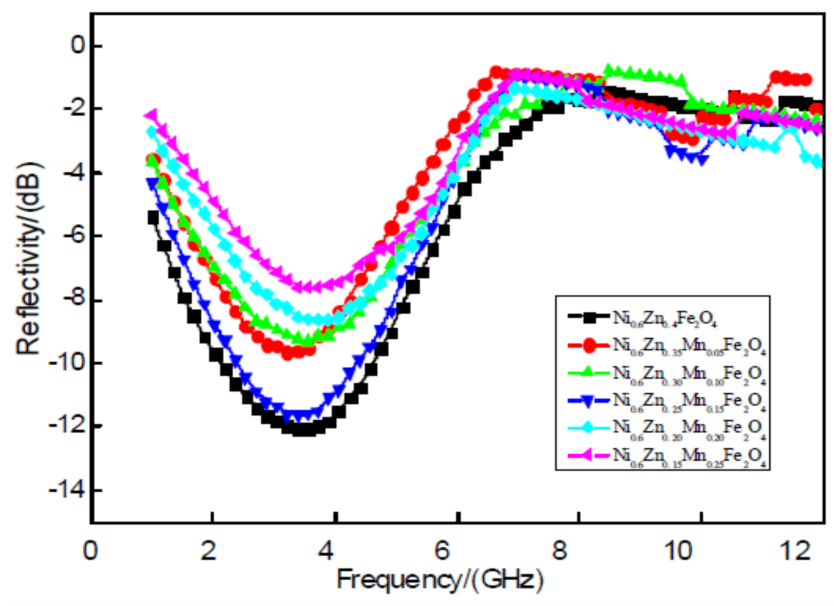

Figure 8. Curves of reflectivity and frequency for the $\mathrm{Ni}_{0.6} \mathrm{Zn}_{(0.4-\mathrm{x})} \mathrm{Mn}_{\mathrm{x}} \mathrm{Fe}_{2} \mathrm{O}_{4}$ sample.

\subsection{The Influence of the Doped $\mathrm{Cu}^{2+}$ Content on the Performance of Nano-Nickel Zinc Ferrite Absorbability}

As can be seen from the Figure 9, five samples of peak type are compared with standard atlas JCPDS and all have the characteristic diffraction peaks of the spinel ferrite. The main diffraction peak position essentially remains unchanged. With an increase in the $\mathrm{Cu}^{2+}$ dopant, the intensity of the main (311) peak at 718.00 and decreases to 496.67. The diffraction peak gradually broadens. While the crystalline degree is smaller, there are different alpha $\mathrm{Fe}_{2} \mathrm{O}_{3}$ diffraction peak intensities in the pattern. The nanometer copper nickel zinc ferrite peaks are impurities. Table 3 shows the copper nickel zinc ferrite grain sizes. The lattice constant increased with an increase in $\mathrm{Cu}^{2+} \mathrm{dopant}^{2}$ while the grain size and lattice constant undergo an opposite change. Because of the copper defects in the lattice, the nickel-zinc ferrite lattice distortion is not conducive to the growth of the lattice constant [21]. The grain size is smaller because the $\mathrm{Cu}^{2+}$ first entered the lattice on the surface of the grain. The surface defects of the grain prevent the combination between grains. This inhibits grain growth. Conversely, due to the contraction of the cell size, the $\mathrm{Cu}^{2+}$ radius is smaller than the radii of $\mathrm{Ni}^{2+}$ and $\mathrm{Zn}^{2+}$, which causes lattice distortion of the nanocrystals and results in a decrease in the cell size. As revealed here, the doped influence of $\mathrm{Cu}^{2+}$ on the structural parameters of the ferrite will affect the material's absorbability.

Figure 10 exhibits a nano $\mathrm{Ni}_{0.6} \mathrm{Zn}_{(0.4-x)} \mathrm{Cu}_{\mathrm{x}} \mathrm{Fe}_{2} \mathrm{O}_{4} \mathrm{TEM}$ diagram. As shown in the figure, the generated nano nickel zinc ferrite morphology has characteristics of the copper quadrilateral structure, grain shape, and size distribution. When the $\mathrm{Cu}^{2+}$ content decreases, the ferrite particles are larger than the unadulterated ones, but the spatial dispersion is still relatively good with decent agglomeration of the material. With an increase in $\mathrm{Cu}^{2+}$ dopant, the grain size is smaller and the agglomeration phenomenon is more dramatic. When the $\mathrm{Cu}^{2+}$ dopant reaches $\mathrm{x}=0.25$, the nanometer copper nickel zinc ferrite grain size changes from $59.63 \mathrm{~nm}$ to $32.46 \mathrm{~nm}$ and the agglomeration phenomenon intensifies. This is because the radius of $\mathrm{Cu}^{2+}$ and $\mathrm{Ni}^{2+}$ are similar. In the reaction, $\mathrm{Cu}^{2+}$ fills the space between the mutual ions and maintains the balance of charge. Through a spin mechanism, it inhibits the growth of particles. With the increase in the $\mathrm{Cu}^{2+}$ dopant, the grain size decreases. At the 
same time, transmission electron microscopy (TEM) sample preparation takes roughly half an hour. Through the ultrasonic oscillations of the scattered material, the sample structure is not damaged, which indicates that the structure itself is very stable.

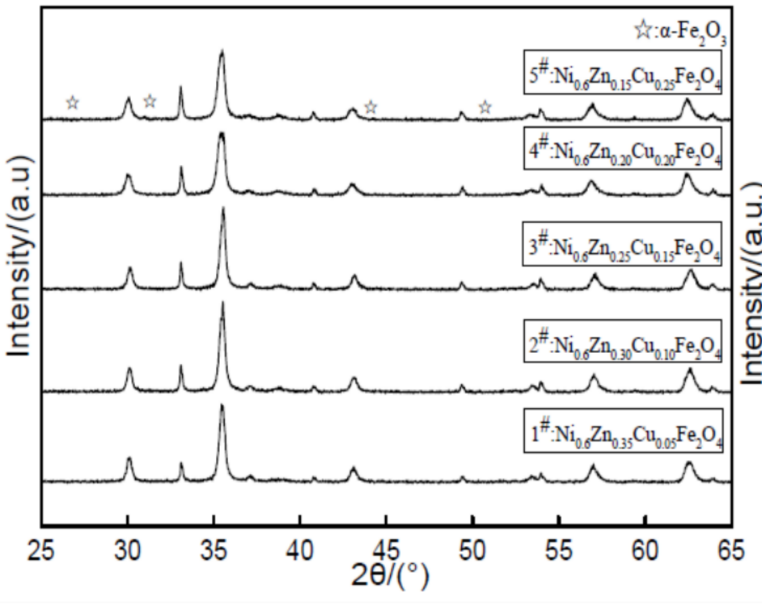

(a)

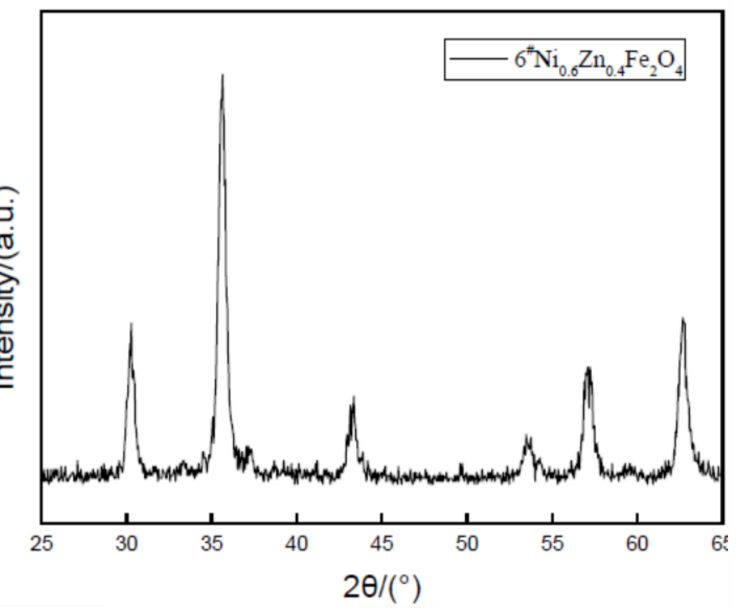

(b)

Figure 9. X-ray diffraction graph patterns of samples prepared with different $\mathrm{Cu}^{2+}$ content (a) and without $\mathrm{Cu}^{2+}$ content $(\mathbf{b})$.

Table 3. Composition and structure parameters of ferrite.

\begin{tabular}{|c|c|c|c|c|c|}
\hline \multirow{2}{*}{ Structural Formula } & \multirow{2}{*}{$2 \theta /\left({ }^{\circ}\right)$} & \multirow{2}{*}{$\begin{array}{c}\text { Lattice } \\
\text { Parameter }\end{array}$} & \multicolumn{3}{|c|}{ (311) Priority Crystallization Diffraction Peak } \\
\hline & & & FWHM/rad & Intensity/a.u. & Size/nm \\
\hline $\mathrm{Ni}_{0.6} \mathrm{Zn}_{0.4} \mathrm{Fe}_{2} \mathrm{O}_{4}$ & 35.62 & 0.8352 & 0.3828 & 468.56 & 20.53 \\
\hline $\mathrm{Ni}_{0.6} \mathrm{Zn}_{0.35} \mathrm{Cu}_{0.05} \mathrm{Fe}_{2} \mathrm{O}_{4}$ & 35.51 & 0.8365 & 0.1384 & 658.67 & 59.63 \\
\hline $\mathrm{Ni}_{0.6} \mathrm{Zn}_{0.30} \mathrm{Cu}_{0.10} \mathrm{Fe}_{2} \mathrm{O}_{4}$ & 35.51 & 0.8370 & 0.1578 & 718.00 & 52.30 \\
\hline $\mathrm{Ni}_{0.6} \mathrm{Zn}_{0.25} \mathrm{Cu}_{0.15} \mathrm{Fe}_{2} \mathrm{O}_{4}$ & 35.56 & 0.8380 & 0.1774 & 654.33 & 46.53 \\
\hline $\mathrm{Ni}_{0.6} \mathrm{Zn}_{0.20} \mathrm{Cu}_{0.20} \mathrm{Fe}_{2} \mathrm{O}_{4}$ & 35.54 & 0.8380 & 0.1971 & 532.67 & 41.87 \\
\hline $\mathrm{Ni}_{0.6} \mathrm{Zn}_{0.15} \mathrm{Cu}_{0.25} \mathrm{Fe}_{2} \mathrm{O}_{4}$ & 35.45 & 0.8390 & 0.2542 & 496.67 & 32.46 \\
\hline
\end{tabular}

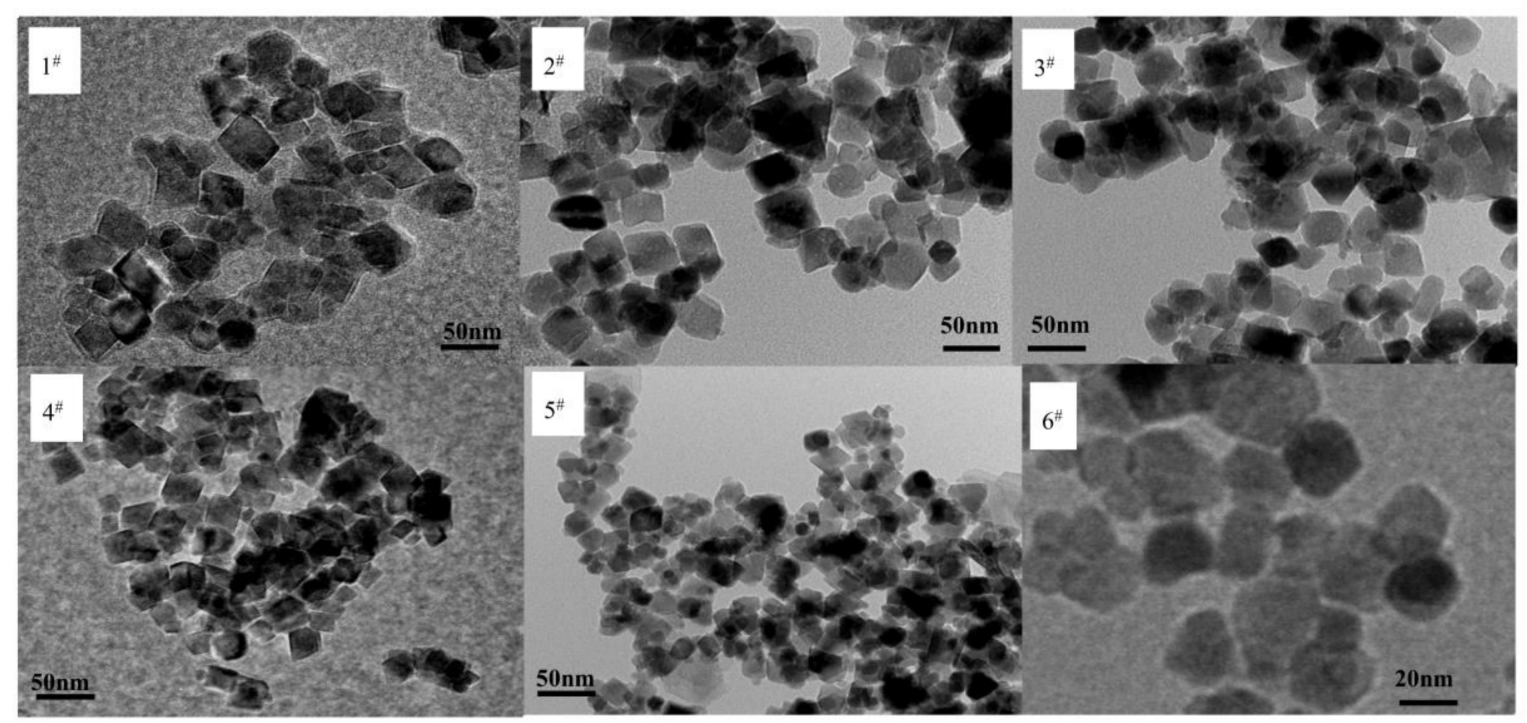

$$
1^{\#} x=0.05 ; 2^{\#} x=0.10 ; 3^{\#} x=0.15 ; 4^{\#} x=0.20 ; 5^{\#} x=0.25 ; 6^{\#} x=0
$$

Figure 10. Transmission electron micrograph of samples prepared with different $\mathrm{Cu}^{2+}$ content. 
Figure 11 shows the loss factor $\tan \delta$ of the nanometer $\mathrm{Ni}_{0.6} \mathrm{Zn}_{(0.4-\mathrm{x})} \mathrm{Cu}_{\mathrm{x}} \mathrm{Fe}_{2} \mathrm{O}_{4}$. The loss factor is overall consistent while the change in frequency first decreases and then increases. There are no special fluctuations, which illustrates that the $\mathrm{Cu}^{2+}$ doping does not affect the effective frequency band range of the nanometer nickel zinc ferrite magnetic loss in the $1 \sim 5 \mathrm{GHz}$ frequency range. With an increase in $\mathrm{Cu}^{2+}$ dopant, the loss factor or tan $\delta$ value decreases after a quick increase and then decreases again. When the $\mathrm{Cu}^{2+}$ content is too low, the tangent essentially goes unchanged. When the doping quantity reaches $x=0.15$, the loss factor of the material, "the tangent of the tangent of the tangent," exhibits a large change, which reaches a maximum of 1.17. This is where the absorbance-wave performance is at the highest value. When the $\mathrm{Cu}^{2+}$ content is too high, the tangent of the tangent is smaller and much less than the unadulterated value. As revealed by a comprehensive analysis of the electromagnetic loss, within the 1 12 GHz band, $\mathrm{Cu}^{2+}$ doping did not improve the absorbance area. The appropriate $\mathrm{Cu}^{2+}$ doping amount is necessary to reach the absorbance performance of the reinforced material. When the $\mathrm{Cu}^{2+}$ dose reaches 0.15 , the nanometer $\mathrm{Ni}_{0.6} \mathrm{Zn}_{0.25} \mathrm{Cu}_{0.15} \mathrm{Fe}_{2} \mathrm{O}_{4}$ is more suitable for electromagnetic dissipation of the electromagnetic waves and, therefore, it performs better.

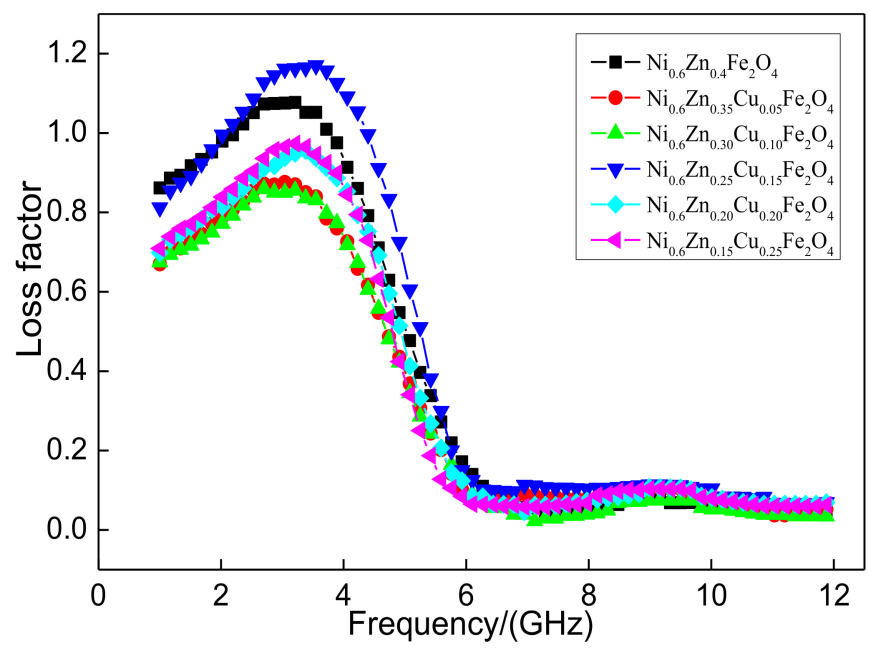

Figure 11. Curves of $\tan \delta$ and frequency for the $\mathrm{Ni}_{0.6} \mathrm{Zn}_{(0.4-\mathrm{x})} \mathrm{Cu}_{\mathrm{x}} \mathrm{Fe}_{2} \mathrm{O}_{4}$ sample.

Figure 12 displays a $2 \mathrm{~mm}$ nanoscale image of the $\mathrm{Ni}_{0.6} \mathrm{Zn}_{(0.4-\mathrm{x})} \mathrm{Cu}_{\mathrm{x}} \mathrm{Fe}_{2} \mathrm{O}_{4}$ material. Within the test range, six samples showed a strong reflectivity absorption peak at $1 \sim 5 \mathrm{GHz}$ frequencies while the other peaks were not as intense. With the addition of $\mathrm{Cu}^{2+}$, the position of the strong peak does not change and the wave band does not widen but instead exhibits a slight narrowing. The $\mathrm{Cu}^{2+} \mathrm{doping}$ amount at $x>0.15$ reveals a greater influence on the reflectivity of the samples. Such reflectivity values of $-10 \mathrm{~dB}$ are obtained near the $3.5 \mathrm{GHz}$ absorbing peak reflectivity from $12.01 \mathrm{~dB}$ down to a dopant concentration of $x=0.15,-13.29 \mathrm{~dB}$. While the absorbance performance improves, the other doping amount of the reflectivity is greater than $12.01 \mathrm{~dB}$. This overall weakens the wave absorption performance of the nanometer nickel zinc ferrite. This may be due to the material's structure. $\mathrm{Zn}^{2+}$ first enters the tetrahedral holes (A) while $\mathrm{Cu}^{2+}$ and $\mathrm{Ni}^{2+}$ prefer to occupy the octahedral holes (B). At the same time, $\mathrm{Fe}^{3+}$ occupies both $\mathrm{A}$ and $\mathrm{B}$ [22]. The magnetic moment of $\mathrm{Fe}^{3+}$ is $5 \mu \mathrm{B}$. The magnetic moment of $\mathrm{Cu}^{2+}(2 \mu \mathrm{B})$ is greater than that of $\mathrm{Zn}^{2+}$, which carries no magnetic moment. Because some $\mathrm{Cu}^{2+}$ ions replace $\mathrm{A}$ and $\mathrm{Zn}^{2+}$, the $\mathrm{B}$ net magnetic moment is reduced, which decreases the magnetic loss and weakens the wave absorption performance. However, just the right amount of $\mathrm{Cu}^{2+}$ could enter the tetrahedral holes by arriving at the location of $\mathrm{Fe}^{3+} \mathrm{A}$. The $\mathrm{B}$ to $\mathrm{B} \mathrm{A}$ net magnetic moment could increase, enhance the A magnetic moment of exchange, and, thereby, increase the magnetic loss. This would then improve wave absorption performance. Therefore, it is possible to apply the appropriate amount of $\mathrm{Cu}^{2+}$ to enhance the absorbing performance of the material. 


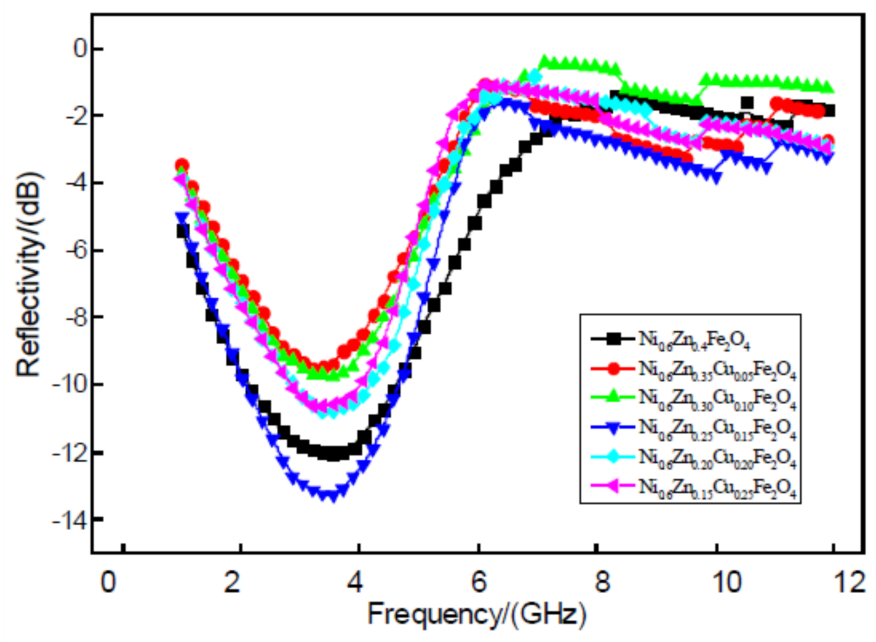

Figure 12. Curves of reflectivity and frequency for the $\mathrm{Ni}_{0.6} \mathrm{Zn}_{(0.4-\mathrm{x})} \mathrm{Cu}_{\mathrm{x}} \mathrm{Fe}_{2} \mathrm{O}_{4}$ sample.

\section{Conclusions}

Nanometer manganese cobalt/nickel zinc/copper ferrite was successfully prepared under the following conditions: the surfactant polyethylene glycol was added to a solution to obtain a $\mathrm{pH}$ value of 10 in which the $\mathrm{Ni}^{2+}$ content was $60 \%$, the iron concentration was $0.33 \mathrm{~mol} / \mathrm{L}$, and the crystallization temperature was $180^{\circ} \mathrm{C}$. The solution then underwent hydrothermal crystallization in $8 \mathrm{~h}$ with $\mathrm{Co}^{2+}$, $\mathrm{Mn}^{2+}$, and $\mathrm{Cu}^{2+}$.

The material was doped with pure $\mathrm{Co}^{2+}$ prepared nano cobalt nickel zinc ferrite. When the $\mathrm{Co}^{2+}$ dopant increased, the original spherical-like grain assumed an irregular quadrilateral structure and the average particle size increased from $35 \mathrm{~nm}$ to $60 \mathrm{~nm}$. For $\mathrm{Ni}_{0.6} \mathrm{Zn}_{0.25} \mathrm{Co}_{0.15} \mathrm{Fe}_{2} \mathrm{O}_{4}$, the reflectivity absorbance changed from $12.01 \mathrm{~dB}$ to $15.05 \mathrm{~dB}$ and the absorbance spectrum width nearly doubled. This resulted in an overall improvement in the material's gigahertz frequency wave absorption performance. Compared to the un-doped material, the electromagnetic loss performance overall decreased and the absorbance wave reflectivity increased while the absorbance effect decreased. There was no profound effect on the doping of $\mathrm{Cu}^{2+}$ nano nickel zinc ferrite on the absorbance spectrum of the electromagnetic loss at 3.5 GHz. Doping of $\mathrm{Mn}^{2+}$ in the nano nickel zinc manganese ferrite does not reach the effect of the wave absorption performance in the reinforced material. $\mathrm{Ni}_{0.6} \mathrm{Zn}_{0.25} \mathrm{Cu}_{0.15} \mathrm{Fe}_{2} \mathrm{O}_{4}$ reached a maximum loss factor of 1.17 and an absorbance reflectivity of $13.29 \mathrm{~dB}$. This material revealed the best wave absorption performance while the other doped analogs in the series did not attain the effect of wave absorption performance in the reinforced material.

Acknowledgments: The project was supported by the National Natural Science Foundation of China (51372108) and the Research Center of Coal Resources Safe Mining and Clean Utilization, LNTU.

Author Contributions: Z.M. and C.M. conceived and designed the experiments; Q.Z. and L.S. performed the experiments; X.W. and C.M. analyzed the data; H.Z. contributed reagents/materials/analysis tools; C.M. wrote the paper. Authorship must be limited to those who have contributed substantially to the work reported.

Conflicts of Interest: The authors declare no conflict of interest.

\section{References}

1. Zhang, Y.; Xiang, X. Effect of Doping Rare-Earth Oxide on microwave Absorbing Properties of Ni-Zn Ferrite/Al-Alloy Forms. J. Rare Earths 2009, 27, 831-836.

2. He, G.H.; Deng, W.L. New progress was made in the study of nanomagnetic absorbing materials. Funct. Mater. Inf. 2005, 2, 8-18. 
3. Wang, J.H.; Liu, Y.C.; Liu, D.C.; Yu, Y.W.; Guo, F.B. Effect of electromagnetic field strength on $\mathrm{Ni}_{0.35} \mathrm{Zn}_{0.65} \mathrm{Fe}_{2} \mathrm{O}_{4}$ as performed by combustion synthesis. J. Magn. Magn. Mater. 2009, 321, 3646-3649. [CrossRef]

4. Zheng, S.F.; Xiong, G.X.; Huang, H.Q. Study on Relatio of Morphology, Properties and Preparations of Ferrites. Mater. Rev. 2009, 12, 26-29.

5. Zhao, X.M.; Liu, Y.J. Dielectric Properties of Ferrite/Silicon Carbide/Graphite Three-layer Composite Coating Materials. J. Mater. Eng. 2017, 1, 33-37.

6. Zhao, H.T.; Zhang, Q.; Liu, R.P.; Ding, X.Y.; Ma, R.T. Synthesis and Magnetic Properties of Monodisperse $\mathrm{ZnFe}_{2} \mathrm{O}_{4}$ Nanoparticles. J. Mater. Eng. 2016, 44, 103-107.

7. Ramesh, S.; Sekhar, B.C.; Rao, P.S.; Rao, B.P. Microstructural and magnetic behavior of mixed Ni-Zn-Co and Ni-Zn-Mn ferrites. Ceram. Int. 2014, 40, 8729-8735. [CrossRef]

8. Zhao, H.T.; Wang, Q.; Liu, R.P.; Ma, R.T. Synthesis and Characterization of MnZn Ferrite at Low Temperature. J. Mater. Eng. 2016, 44, 73-77.

9. Xiong, Z.; Liu, L.; Hu, H.; Zhang, S.A. Influence of Ion Doping on Electromagnetic Property of W-type Ba-Ferrite. J. Mater. Sci. Eng. 2013, 31, 664-667.

10. Gama, A.M.; Rezende, M.C.; Dantas, C.C. Dependence of microwave absorption properties on ferrite volume fraction in MnZn ferrite/rubber radar absorbing materials. J. Magn. Magn. Mater. 2011, 323, 2782-2785. [CrossRef]

11. Shinde, T.J.; Gadkari, A.B.; Vasambekar, P.N. Magnetic properties and cation distribution study of nanocrystalline Ni-Zn ferrites. J. Magn. Magn. Mater. 2013, 333, 152-155. [CrossRef]

12. Kumar, S.; Kumar, P.; Singh, V.; Mandal, U.K.; Kotnala, R.K. Synthesis characterization and magnetic properties of monodisperse Ni, Zn-ferrite nanocrystals. J. Magn. Magn. Mater. 2015, 379, 50-57. [CrossRef]

13. Liu, S.; Wang, L.; Chou, K. Synthesis of metal-doped Mn-Zn ferrite from the leaching solutions of vanadium slag using hydrothermal method. J. Magn. Magn. Mater. 2018, 449, 49-54. [CrossRef]

14. Huo, J.Z.; Wei, M.Z. Characterization and magnetic properties of nanocrystalline nickel ferrite synthesized by hydrothermal method. Mater. Lett. 2009, 63, 1183-1184. [CrossRef]

15. Zhong, Z.F.; Li, Q.; Zhang, Y.L. Synthesis of nanocrystalline Ni-Zn ferrite powders by refluxing method. Powder Technol. 2005, 155, 193-195. [CrossRef]

16. Ni, D.; Lin, Z.; Xiaoling, P.; Xinqing, W.; Hongliang, G. Preparation and Characterization of Nickel-Zinc Ferrites by a Solvothermal Method. Rare Met. Mater. Eng. 2015, 44, 2126-2131. [CrossRef]

17. Wang, H.W.; Kung, S.C. Crystallization of nanosized Ni-Zn ferrite powders prepared by hydrothermal method. Chem. J. Chin. Univ. 2004, 270, 230-236. [CrossRef]

18. Aphesteguy, J.C.; Damiani, A.; DiGiovanni, D.; Jacobo, S.E. Microwave absorbing character-istics of epoxy resin composites containing nanoparticles of NiZn- and NiCuZn-ferrites. Phys. B Condens. Matter 2009, 404, 2713-2716. [CrossRef]

19. Wang, S.F.; Hsu, Y.F.; Chou, K.M.; Tsai, J.T. Effects of co-dopants on the magnetic properties of Ni-Zn ferrites. J. Magn. Magn. Mater. 2015, 374, 402-410. [CrossRef]

20. Azhagushanmugama, S.J.; Suriyanarayanan, N.; Jayaprakash, R. Synthesis and Characterization of Nan-ocrystalline $\mathrm{Ni}_{(0.6)} \mathrm{Zn}_{(0.4)} \mathrm{Fe}_{2} \mathrm{O}_{4}$ Spinel Ferrite Magnetic Material. Phys. Procedia 2013, 49, $44-48$. [CrossRef]

21. Alvarez, G.; Montiel, H.; Barron, J.F.; Gutierrez, M.P.; Zamorano, R. Yafet-Kittel-type magnetic ordering in $\mathrm{Ni}_{0.35} \mathrm{Zn}_{0.65} \mathrm{Fe}_{2} \mathrm{O}_{4}$ ferrite detected by magnetosensitive microwave absorption measurements. J. Magn. Magn. Mater. 2010, 322, 348-352. [CrossRef]

22. Weng, X.; Zhang, Q.; Wang, J.; Su, W.; Ma, Z. Absorption Properties of Composite Materials for the Encapsulation of Nano Ferroferric Oxide in Mesoporous Materials. Curr. Org. Chem. 2016, 20, 1143-1147. [CrossRef]

(C) 2018 by the authors. Licensee MDPI, Basel, Switzerland. This article is an open access article distributed under the terms and conditions of the Creative Commons Attribution (CC BY) license (http:/ / creativecommons.org/licenses/by/4.0/). 